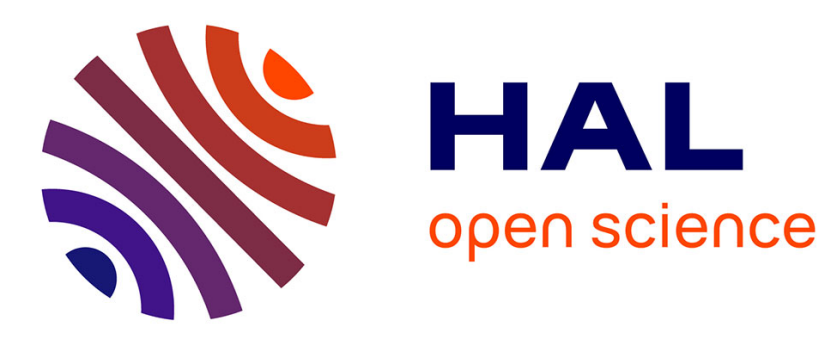

\title{
Maximum curvatures of $0 / 90$ plates under thermal stress: modelling and experimental validation
}

\author{
M. Gigliotti, J. Molimard, F. Jacquemin, A. Vautrin
}

\section{To cite this version:}

M. Gigliotti, J. Molimard, F. Jacquemin, A. Vautrin. Maximum curvatures of 0/90 plates under thermal stress: modelling and experimental validation. Composites Science and Technology, 2008, 69 (1), pp.93. 10.1016/j.compscitech.2007.10.054 . hal-00499002

\section{HAL Id: hal-00499002 https://hal.science/hal-00499002}

Submitted on 9 Jul 2010

HAL is a multi-disciplinary open access archive for the deposit and dissemination of scientific research documents, whether they are published or not. The documents may come from teaching and research institutions in France or abroad, or from public or private research centers.
L'archive ouverte pluridisciplinaire HAL, est destinée au dépôt et à la diffusion de documents scientifiques de niveau recherche, publiés ou non, émanant des établissements d'enseignement et de recherche français ou étrangers, des laboratoires publics ou privés. 


\section{Accepted Manuscript}

Maximum curvatures of 0/90 plates under thermal stress: modelling and experimental validation

M. Gigliotti, J. Molimard, F. Jacquemin, A. Vautrin

PII: S0266-3538(07)00445-9

DOI: 10.1016/j.compscitech.2007.10.054

Reference: CSTE 3894

To appear in: Composites Science and Technology

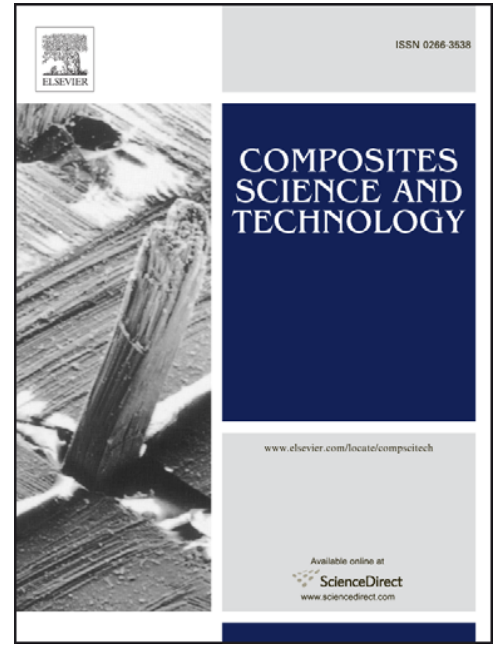

Received Date: $\quad 18$ July 2007

Accepted Date: $\quad 11$ October 2007

Please cite this article as: Gigliotti, M., Molimard, J., Jacquemin, F., Vautrin, A., Maximum curvatures of 0/90 plates under thermal stress: modelling and experimental validation, Composites Science and Technology (2007), doi: 10.1016/j.compscitech.2007.10.054

This is a PDF file of an unedited manuscript that has been accepted for publication. As a service to our customers we are providing this early version of the manuscript. The manuscript will undergo copyediting, typesetting, and review of the resulting proof before it is published in its final form. Please note that during the production process errors may be discovered which could affect the content, and all legal disclaimers that apply to the journal pertain. 


\title{
MAXIMUM CURVATURES OF 0/90 PLATES UNDER THERMAL STRESS: MODELLING AND EXPERIMENTAL VALIDATION
}

\author{
M. Gigliotti*,a , J. Molimard*, F. Jacquemin** and A. Vautrin* \\ * Département Mécanique et Matériaux, \\ École Nationale Supérieure des Mines de Saint-Étienne, \\ 158 Cours Fauriel 4200 Saint-Étienne, FRANCE. \\ vautrin@emse.fr \\ ** Institut de Recherche en Génie Civil et Mécanique (GeM), \\ Université de Nantes, \\ Boulevard de l'Université, BP 406, 44602 Saint-Nazaire, FRANCE. \\ jacquemin@lamm.univ-nantes.fr
}

\section{ABSTRACT}

In this paper, special attention is paid to the maximum curvatures induced by uniform thermal fields in $0_{\mathrm{m}} / 90_{\mathrm{n}}$ laminated square plates. The effects of the relative thickness of the $90^{\circ}$ ply $\mathrm{e}_{90}$ and of the elastic and thermoelastic anisotropy on the curvature tensor are then studied. The conditions for which the curvatures are maximum are established by adopting the polar method within the context of the classical lamination theory. It is found that the location of the maximum curvatures is influenced by the level of elastic anisotropy, defined by the polar parameter $R_{l}$, while the magnitude of the maximum curvatures is driven by the thermoelastic properties, that is, the coefficients of thermal expansion. The capabilities of a geometrical non-linear model are explored and experimental evidence of maximum curvatures of glass/epoxy composite materials are provided.

a, current address: Centro Italiano Ricerche Aerospaziali (CIRA)

Via Maiorise, 81043, Capua (Ce), ITALY 
KEYWORDS : A. POLIMER-MATRIX COMPOSITES, C. LAMINATE THEORY, RESIDUAL STRESS

\section{INTRODUCTION}

$0_{\mathrm{m}} / 90_{\mathrm{n}}$ unsymmetric composite plates under thermal stress deform because of the thermoelastic coupling. Indeed, the curing temperature of such plates is different from the service ambient temperature, therefore the temperature differential $\left(\mathrm{T}_{\text {cure }}-\mathrm{T}_{\text {room }}\right)$ produces consistent thermal loads (thermal forces and moments) and curvatures. Curvature measurements are utilized to determine curing stresses ([1-2]). The basic idea is to identify the laminate stacking sequences allowing to perform optimal experiments due to their high sensitivity to external loads. Also, it would be desirable in preliminary design of structures to design plates that have a desired deformed shape when subjected to thermal solicitations.

Vannucci [3-4] studied in detail the phenomenon of elastic and thermoelastic coupling, that is, the structure of $\mathbf{B}$ and $\mathbf{V}$ tensors of the classical laminated plate theory (CLPT, [5]). He employed the polar method, making use of invariant quantities of such tensors; in particular, by this analytical method he was able to determine explicit expressions for their maximum norms.

In the present paper, the approach already employed by Vannucci is extended to the curvature tensors $k$, whose components are maximised 
for plates belonging to the $0_{\mathrm{m}} / 90_{\mathrm{n}}$ family. A geometrical nonlinear model of plates is then used to verify the applicability range of the simple linear theory. The paper is divided as follows : first, the employed models are briefly recalled, then the results of some simulations are presented and, finally, experimental results validating the models are provided.

\section{MODEL DESCRIPTION}

\subsection{Recall of the polar method and conditions of maximum coupling}

The Cartesian components of the anisotropic stiffness tensor, $\mathbf{Q}$, of a composite ply may be expressed in their polar form [3] by employing the 6 parameters $T_{0}, T_{1}, R_{0}, R_{1}, \Phi_{0}$ and $\Phi_{1}$ as follows:

$$
\begin{aligned}
& Q_{x x}=T_{0}+2 T_{1}+R_{0} \cos 4 \Phi_{0}+4 R_{1} \cos 2 \Phi_{1} \\
& Q_{x y}=-T_{0}+2 T_{1}-R_{0} \cos 4 \Phi_{0} \\
& Q_{y y}=T_{0}+2 T_{1}+R_{0} \cos 4 \Phi_{0}-4 R_{1} \cos 2 \Phi_{1} \\
& Q_{s s}=T_{0}-R_{0} \cos 4 \Phi_{0} \\
& Q_{x s}=R_{0} \sin 4 \Phi_{0}+2 R_{1} \sin 2 \Phi_{1} \\
& Q_{y s}=-R_{0} \sin 4 \Phi_{0}+2 R_{1} \sin 2 \Phi_{1}
\end{aligned}
$$

with,

$$
\begin{aligned}
& 8 T_{0}=Q_{x x}-2 Q_{x y}+4 Q_{x s}+Q_{y y} \\
& 8 T_{1}=Q_{x x}+2 Q_{x y}+Q_{y y} \\
& 8 R_{0} e^{4 i \Phi_{0}}=Q_{x x}-2 Q_{x y}-4 Q_{s s}+Q_{y y}+4 i\left(Q_{x s}-Q_{s s}\right) \\
& 8 R_{1} e^{2 i \Phi_{1}}=Q_{x x}-Q_{y y}+2 i\left(Q_{x s}+Q_{s s}\right)
\end{aligned}
$$

The following statements can be formulated: 
- $\quad T_{0}, T_{1}, R_{0}, R_{1}$ and $\Phi_{0}-\Phi_{1}$ are invariant under a rotation $\theta$ with respect to the reference frame,

- a material is isotropic if $R_{0}=R_{1}=0 . T_{0}$ and $T_{1}$ constitute the isotropic parts of $\mathbf{Q}$, while $R_{0}, R_{1}, \Phi_{0}, \Phi_{1}$ constitute its anisotropic part,

- $\mathbf{Q}$ is orthotropic if and only if $\left(\Phi_{0}-\Phi_{1}\right)=k \pi / 4$ with $k$ integer.

The equations of the classical plate lamination theory state that [5]:

$$
\begin{aligned}
& \mathbf{N}=\mathbf{A} \varepsilon_{0}+\mathbf{B} k-\mathbf{U} \Delta T \\
& \mathbf{M}=\mathbf{B} \varepsilon_{0}+\mathbf{D} k-\mathbf{V} \Delta T
\end{aligned}
$$

Invariant quantities analogous to those defined in equation (2) can be introduced tensors for $\mathbf{A}, \mathbf{B}, \mathbf{D}, \mathbf{U}, \mathbf{V}$, respectively $\bar{T}_{0}, \bar{T}_{1}, \bar{R}_{0}, \bar{R}_{1}, \bar{\Phi}_{0}, \bar{\Phi}_{1}$ for $\mathbf{A}, \hat{T}_{0}, \hat{T}_{1}, \hat{R}_{0}, \hat{R}_{1}, \hat{\Phi}_{0}, \hat{\Phi}_{1}$ for $\mathbf{B}, \tilde{T}_{0}, \tilde{T}_{1}, \tilde{R}_{0}, \tilde{R}_{1}, \widetilde{\Phi}_{0}, \widetilde{\Phi}_{1}$ for $\mathbf{D}, \bar{T}, \bar{R}, \bar{\Phi}$ for $\mathbf{U}$ and $\hat{T}, \hat{R}, \hat{\Phi}$ for $\mathbf{V}$. The reader can refer to the work by Vannucci et al. [3] for more detail about the exact definition of such quantities. Here, we simply note that tensors $\mathbf{B}$ and $\mathbf{V}$ represent, respectively elastic and thermoelastic coupling.

Finally the norm of a fourth order tensor (A for instance) can be defined by the following expression: 


$$
A=\sqrt{\bar{T}_{0}^{2}+2 \bar{T}_{1}^{2}+\bar{R}_{0}^{2}+4 \bar{R}_{1}^{2}}
$$

In the following sections we will consider laminates with identical plies, for which:

$$
\hat{T}_{0}=\hat{T}_{1}=\hat{T}=0
$$

According to Vannucci [4], a laminate is decoupled if the tensor norms $B$ and $V$ (pertaining, respectively to tensors $\mathbf{B}$ and $\mathbf{V}$ ) are equal to zero: it is important to note that - for laminates with identical plies - the condition $\mathbf{B}=0$ implies $\mathbf{V}=0$, while the inverse is not true.

Vannucci [4], by using the polar method, established explicitly the conditions of maximum coupling, that can be read as follows:

- the thermoelastic coupling is maximum (max. $V$ ) when all plies belonging to each half of the stacking sequence, with respect to the middle plane, have the same orientation differing by an angle equal to $\pi / 2$ : this result is not influenced by the material properties,

- the conditions of maximum elastic coupling (max. B) are the same as for $V$ only if $\rho=R_{0} / R_{1} \leq 1$; on the contrary, max. $B$ is reached with plates whose halves differ by an angle $\delta$ equal to: 


$$
\delta=\frac{1}{2} \arccos \left(-\frac{1}{\rho^{2}}\right)
$$

This time, material properties have an important influence on the maximum coupling. In fact, for laminates with $\rho>1, B$ and $V$ are not maximised by the same stacking sequence.

\subsection{Maximum curvatures of $0_{\mathrm{m}} / 90_{\mathrm{n}}$ plates}

By re-writing the constitutive equation (3) using the polar formalism and by employing invariant quantities for the thermal forces and moments we obtain, for a laminate belonging to the $0_{\mathrm{m}} / 90_{\mathrm{n}}$ family:

$$
\left(\begin{array}{l}
T_{N} \\
R_{N} \\
T_{M} \\
R_{M}
\end{array}\right)=\left(\begin{array}{cccc}
4 \bar{T}_{1} & 4 \bar{R}_{1} & 0 & 4 \hat{R}_{1} \\
4 \bar{R}_{1} & 2\left(\bar{T}_{0}+\bar{R}_{0}\right) & 4 \hat{R}_{1} & 0 \\
0 & 4 \hat{R}_{1} & 4 \tilde{T}_{1} & 4 \tilde{R}_{1} \\
4 \hat{R}_{1} & 0 & 4 \tilde{R}_{1} & 2\left(\tilde{T}_{0}+\tilde{R}_{0}\right)
\end{array}\right)\left(\begin{array}{c}
T_{\varepsilon} \\
R_{\varepsilon} \\
T_{k} \\
R_{k}
\end{array}\right)
$$

$T_{\varepsilon}, R_{\varepsilon}, T_{k}, R_{k}$ can be determined by inverting equation (7) and curvatures $k_{x x}$ and $k_{y y}$ can be obtained by the following equations:

$$
T_{k}=\frac{k_{x x}+k_{y y}}{2}, \quad R_{k}=\frac{k_{x x}-k_{y y}}{2}
$$

It has to be noted that, for laminates belonging to the $0_{\mathrm{m}} / 90_{\mathrm{n}}$ family under thermal solicitations the twisting curvature $k_{x y}$ is equal to zero, because there are no shear and twisting thermal solicitations, respectively $N_{x y}^{\text {th }}$ and $M_{x y}^{\text {th }}$ to activate them. 
The curvatures can be studied as functions of the adimensional thickness (with respect to the total thickness of the plate, $e$ ) of the $90^{\circ}$ plies, $e_{90}$, and the value of $e_{90}$ for which curvatures are maximum can be explicitly assessed by means of analytical expressions.

For instance, the maximum $k_{x x}$ is given by a value of $e_{90}$ which is solution of the following equation:

$$
8 R_{1} e_{90}^{2}-2\left(T_{0}+2 T_{1}+R_{0}-4 R_{1}\right) e_{90}+\left(T_{0}+2 T_{1}+R_{0}-4 R_{1}\right)=0
$$

One of the solutions of equation (9) does not belong to the interval $[0,1]$ within which $e_{90}$ is varying; the other solution is the searched value, $e_{90 \max }$ : it has to be noted that solutions of equation (9) are always real, whatever the material properties.

For $k_{y y}$ an analogous equation can be established. In fact, $k_{y y}$ is maximum for a value of $e_{90}$ which is the solution of the following equation:

$$
8 R_{1} e_{90}^{2}+2\left(T_{0}+2 T_{1}+R_{0}-4 R_{1}\right) e_{90}-\left(T_{0}+2 T_{1}+R_{0}-4 R_{1}\right)=0
$$

Maximum curvatures $\left(k_{x x}\right.$ or $\left.k_{y y}\right)$ depend by elastic invariant properties of a ply: a very important role is played by the parameter $R_{1}$ which is an indicator of the anisotropy of the material. It is evident that for $R_{1}=0$ (elastic isotropy) the problem admits only one solution, that is, 
$e_{90 \max }=0.5:$ in other words, for such a material the maximum curvature of $0_{m} / 90_{n}$ plates is reached for $m=n$.

Figure 1 presents the evolution of the adimensional curvatures (that is, multiplied by the total thickness of the plate), $k_{x x}$ and $k_{y y}$, as functions of $e_{90}$ : the simulations are performed for a carbon-epoxy composite material, which exhibits a marked anisotropic behaviour, and whose properties are presented in table 1.

For $e_{90}=0.5, k_{x x}$ and $k_{y y}$ have the same magnitude and opposite sign. The maximum values of $k_{x x}$ and $k_{y y}$ are reached for values of $e_{90}$ which are respectively equal to 0,81 and 0,19 . These values are coincident with those determined by the analytical equations (9) and (10). It has to be noted that, for the considered material (for which $\rho<1$ ), the conditions of maximum coupling established by Vannucci do not correspond to the conditions of maximum curvatures.

Figure 2 shows the effect of the parameter $R_{1}$ on the location of the maximum curvature. By increasing $R_{1}$, that is, the level of elastic anisotropy of the material, the value of $e_{90 \max }$ moves towards the external limits of the $[0,1]$ interval.

Moreover, we note that the thermoelastic properties of a ply, that is, the coefficients of thermal expansion, have no role on the location of 
the maximum curvatures. On the other hand, the difference $\Delta \alpha=\left(\alpha_{2}-\alpha_{1}\right)$, between the transverse and longitudinal thermal expansion coefficients, have a consistent influence on the magnitude of the maximum curvatures.

\section{EXPERIMENTAL MEASURES}

The curvatures of several composite plates, made by glass-epoxy Ec13/913 materials and with several values of thickness of the $90^{\circ}$ plies, have been measured by using the experimental technique detailed in reference [1]; measurements have been compared to numerical predictions and results are presented in figure 3. The material properties of this material have been measured at several temperatures (see table 2) and predictions by the model have employed such values. Measures do not agree - qualitatively and quantitatively - with the predictions of the linear theory. However, they are in good agreement with a plate theory that takes into account geometrical nonlinearities [6]. On the other hand, the value of $e_{90 \max }$ is not affected by geometrical nonlinearities and is in good agreement with the experimental measures.

Figure 3 shows the typical behaviour of this kind of plates; the deformed shapes are not saddle-like, as predicted by the linear theory, but cylindrical. Actually two cylindrical deformed shapes, the first one along the $\mathrm{x}$ direction and the other one along the $\mathrm{y}$ direction may exist: in fact, at 
a given temperature, for the same total potential energy, the two cylindrical deformed shapes are both allowed to exist. The prevalence of one solution with respect to the other is dictated by imperfections: the range of existence of the two cylindrical solutions is clearly indicated in figure 3 .

\section{CONCLUSIONS}

The behaviour of composite laminated plates belonging to the $0_{\mathrm{m}} / 90_{\mathrm{n}}$ family under thermal loads has been studied with the aim of determining their maximum thermally induced curvatures. The classical plate lamination theory (a linear theory) and the polar method were employed. These methods allowed us to find explicitly the conditions of maximum curvature. In particular, the thickness of the $90^{\circ}$ plies, $e_{90}$, for which curvatures are maximum were determined. The location of maximum curvature (i.e. $e_{90 M A X}$ ) depends on the elastic properties of a ply while their magnitude is driven by the thermal expansion coefficients, that is, by the thermoelastic properties.

The existence of maximum curvatures has been experimentally proven through measures of curvatures of laminated plates made by glassepoxy Ec13/913 composite materials. The location of maximum 
curvatures is correctly predicted by the linear models; on the other hand, the magnitude of the measured curvatures agree with a model of plates which takes into account the effect of geometrical nonlinearities. This result is plausible, since these plates exhibit large displacements, even at small strain.

\section{REFERENCES}

[1] Gigliotti M., Molimard J., Jacquemin F. et Vautrin A., 2006. "On the Nonlinear Deformations of Thin Unsymmetric 0/90 Plates Under Hygrothermal Loads", Composites Part A: Applied Science and Manufacturing. v. 37, pp. 624-629.

[2] Gigliotti M., Jacquemin F. et Vautrin A., 2005. " On the Maximum Curvatures of 0/90 Plates Under Thermal Loads ", Composites Structures. v. 68 , pp. $177-184$.

[3] Vannucci P. et Verchery G., 2001. "Stiffness Design of Laminates Using the Polar Method ", International Journal of Solids and Structures, v. 38 , pp. $9281-9294$.

[4] Vannucci P., 2001. "On Bending - Tension Coupling of Laminates", Journal of Elasticity, v. 64, pp. 16-28.

[5] Herakovitch, C.T. 1998 "Mechanics of Fibrous Composites", John Wiley and Sons, New York. 


\section{ACCEPTED MANUSCRIPT}

[6] Gigliotti, M., Wisnom, M. R., Potter, K. D., 2004. "Loss of Bifurcation and Multiple Shapes of Thin [0/90] Unsymmetric Composite Plates Subject to Thermal Stress.", Composites Science and Technology. v.64, pp. 109-128. 


\section{List of Figures.}

Figure 1 : Adimensional $k_{x x}(-)$ and $k_{y y}(\diamond \diamond \diamond)$ as functions of $\mathrm{e}_{90}$ (carbon-epoxy).

Figure 2: Adimensional $k_{x x}\left(-\right.$ )as a function of $\mathrm{e}_{90}$ and $R_{1}$.

Figure 3: Comparison between model predictions and experimental measurements (Ec13/913 glass-epoxy material). 


\section{List of Tables.}

Table 1: Thermomechanical properties used in the simulations.

Table 2 : Thermomechanical properties (at $\mathrm{T}_{\mathrm{amb}}$ ) of the glass-epoxy Ec13/913 composite material. 


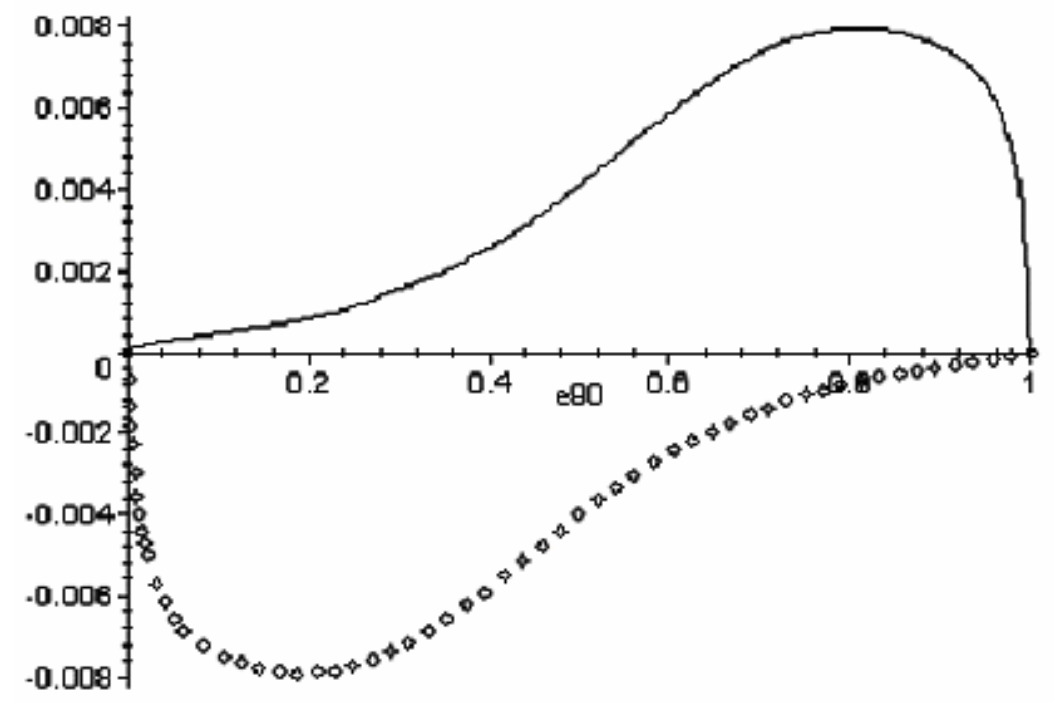

Figure 1 : Adimensional $k_{x x}(-)$ and $k_{y y}(\diamond \diamond \diamond)$ as functions of $\mathrm{e}_{90}$ (carbon-epoxy).

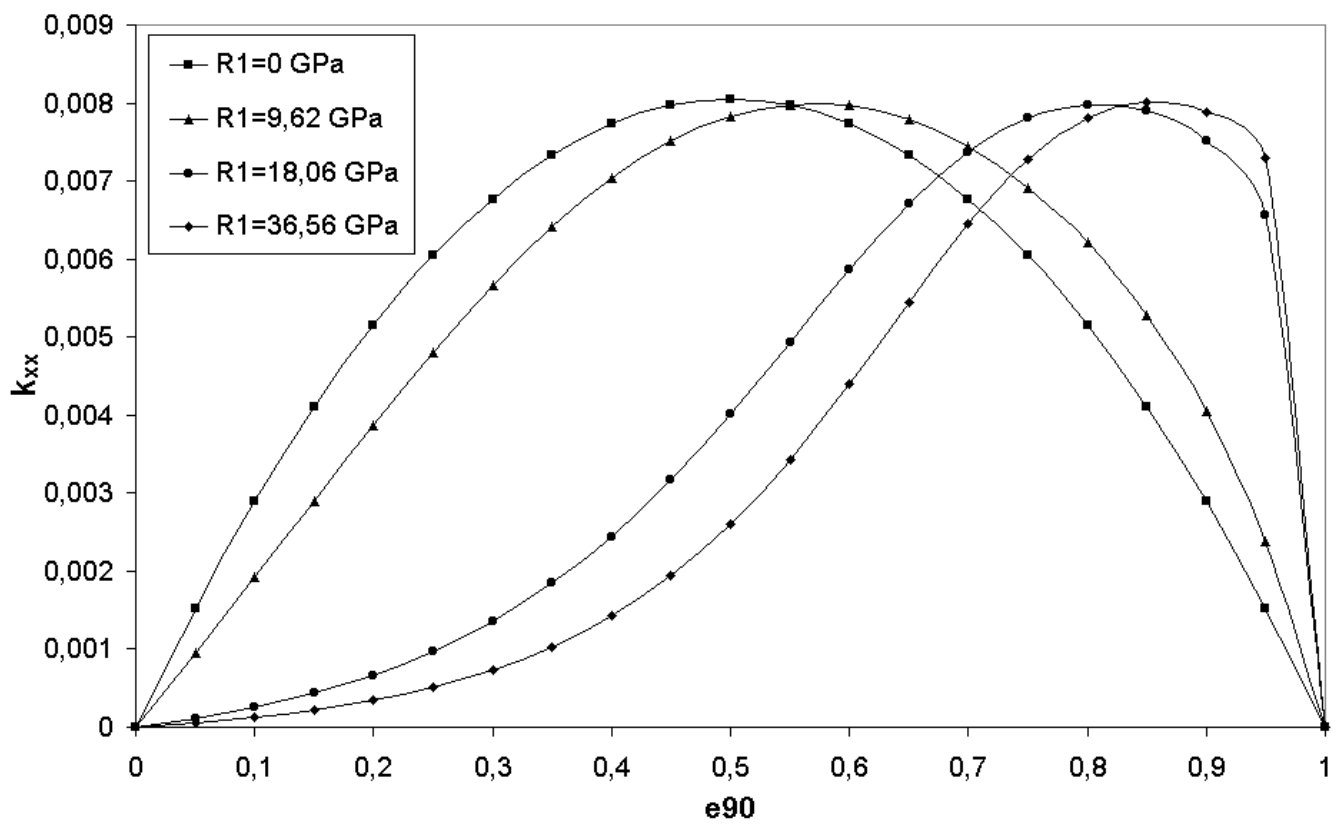

Figure 2 : Adimensional $k_{x x}(-)$ as a function of $\mathrm{e}_{90}$ and $R_{1}$. 


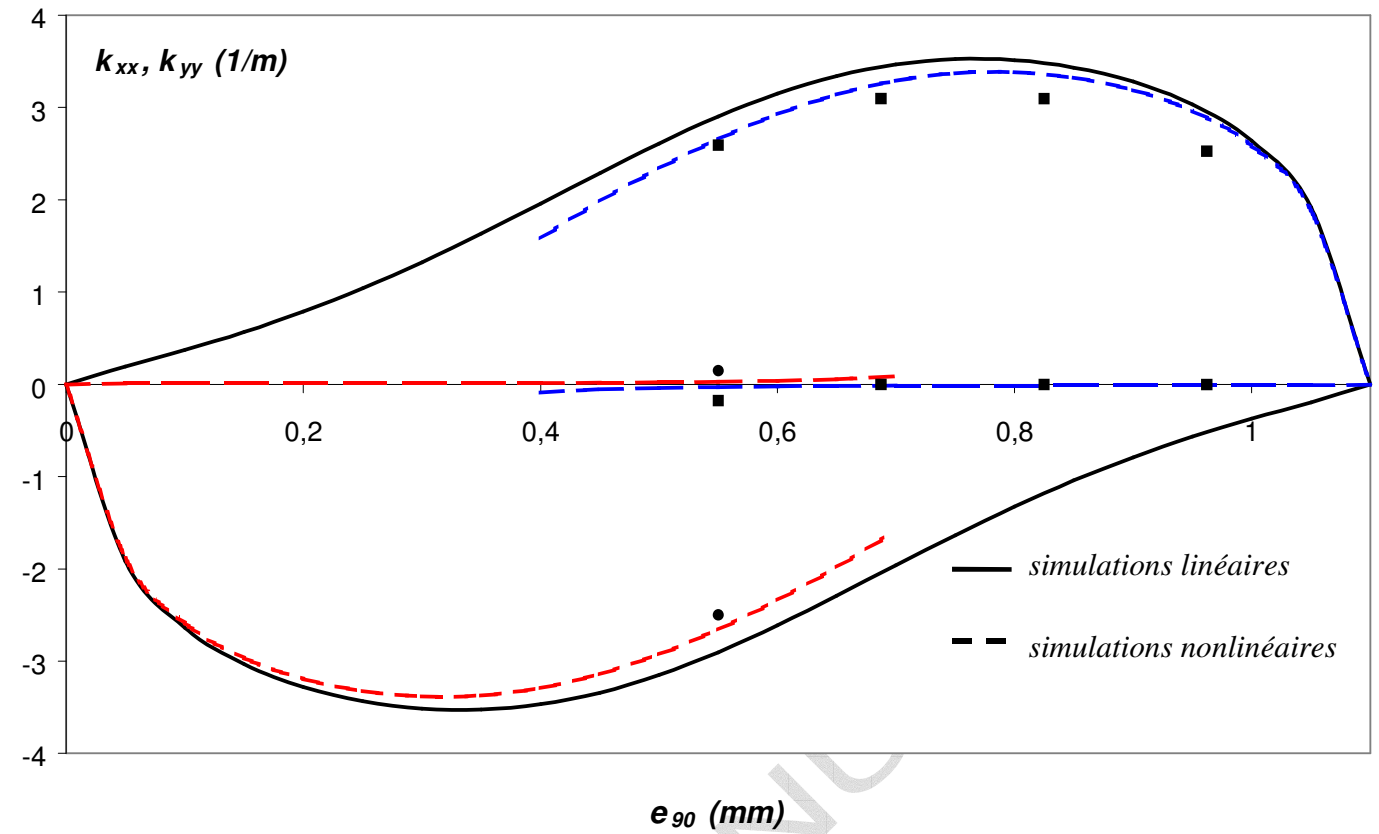

Figure 3: Comparison between model predictions and experimental measurements (Ec13/913 glass-epoxy material). 


\begin{tabular}{|c|c|c|c|c|c|}
\hline$E_{1}(\mathrm{GPa})$ & $E_{2}(\mathrm{GPa} a$ & $G_{12}(\mathrm{GPa})$ & $v_{12}$ & $\alpha_{1}\left({ }^{\circ} \mathrm{C}^{-1}\right)$ & $\alpha_{2}\left({ }^{\circ} \mathrm{C}^{-1}\right)$ \\
\hline 152 & 8.4 & 4.2 & 0.35 & $0.09 \mathrm{E}-6$ & $28.8 \mathrm{E}-6$ \\
\hline$T_{0}$ & $T_{1}$ & $R_{0}$ & $R_{1}$ & $\Phi_{0}$ & $\Phi_{1}$ \\
\hline 21.5 & 20.9 & 17.3 & 18 & 0 & 0 \\
\hline
\end{tabular}

Table 1: Thermomechanical properties used in the simulations.

\begin{tabular}{|c|c|c|c|c|c|}
\hline$E_{1}(\mathrm{GPa})$ & $E_{2}(\mathrm{GPa} a$ & $G_{12}(\mathrm{GPa} a$ & $v_{12}$ & $\alpha_{1}\left({ }^{\circ} \mathrm{C}^{-1}\right)$ & $\alpha_{2}\left({ }^{\circ} \mathrm{C}^{-1}\right)$ \\
\hline 45.8 & 8.1 & - & - & $7.12 \mathrm{E}-6$ & $29.7 \mathrm{E}-6$ \\
\hline$T_{0}$ & $T_{1}$ & $R_{0}$ & $R_{1}$ & $\Phi_{0}$ & $\Phi_{1}$ \\
\hline 8.4 & 7.3 & 4.2 & 4.7 & 0 & 0 \\
\hline
\end{tabular}

Table 2: Thermomechanical properties (at $\mathrm{T}_{\mathrm{amb}}$ ) of the glass-epoxy Ec13/913 composite material. 